\title{
Shiba Inu
}

National Cancer Institute

\section{Source}

National Cancer Institute. Shiba Inu. NCI Thesaurus. Code C53865.

The Shiba Inu is a small, compact, furry dog with a pointed face, broad forehead and triangular prick ears. It has a Spitz-like tail curling over the back. The double coat most often comes in red, or red with a little black overlay, or black with tan markings. The dog should have white or cream-colored markings on the cheeks and sides of the muzzle, throat, underside and chest. White is also possible on the legs, tail tip and above the eyes. Height:13-16 inches (33-41 cm.) Weight: 18-30 pounds (8-14 kg.) 